\title{
IMPLEMENTASI KOMUNIKASI PEMASARAN TERPADU PADA YAYASAN NURUL IBAD JAKARTA TIMUR
}

\author{
Ruzqiyah Ulfa \\ Mahasiswa Progam Doktor Ilmu Komunikasi, Universitas Sahid Jakarta \\ Alamat surel: ruzqiyahulfa@gmail.com \\ Rustono Farady Marta \\ Mahasiswa Progam Doktor Ilmu Komunikasi, Universitas Indonesia \\ Alamat surel: rustonofarady@gmail.com
}

\begin{abstract}
Study about Integrated Marketing Communication or IMC has become a common issues. Not just profitoriented institutions, non-profit institutions also need to know the communication strategy of the "new generation". The strategy in this integrated marketing communications that drive every aspect of the communication process to reach customers or the public with a message of unity in offering a benefit and ideas. Certainly not an easy thing when having a lot of media, ideas, activities and plans, but should have one "message" only. The integration process of marketing communication activities summarized simply by Chriss Fill (1995) through the integration of process models and marketing communication activities Hermawan Kertajaya in "3i Marketing Triangle" and "32 Values-Based Matrix". The Practice of marketing and social marketing products by Andreason, the emphasis is on the wider community that directly affect to the behavior and the needs or interests of the target as a basis. Yayasan Nurul Ibad as a non profit organization builds its brand image through their service by using marketing communication mix that consists of eight major communication model proposed by Philiph Kotler.
\end{abstract}

Keywords: Integrated Marketing Communication, Message, Nurul Ibad

\begin{abstract}
Abstrak
Studi mengenai komunikasi pemasaran terpadu atau Integrated Marketing Communication (IMC) sudah menjadi kajian yang ramai dibicarakan. Tidak hanya lembaga yang berorientasi profit saja, lembaga nirlaba pun perlu mengetahui strategi komunikasi "generasi baru". Strategi dalam komunikasi pemasaran terpadu ini yang mendorong setiap aspek proses komunikasi untuk menjangkau pelanggan atau masyarakat dengan kesatuan pesan dalam menawarkan suatu manfaat dan ide. Tentunya bukan hal yang mudah apabila mempunyai banyak media, ide, kegiatan serta rencana, akan tetapi harus mempunyai satu kesatuan "pesan" saja. Proses integrasi kegiatan komunikasi pemasaran diringkas secara sederhana oleh Chriss Fill (1995) melalui model proses integrasi kegiatan komunikasi pemasaran dan Hermawan Kertajaya dalam " $3 i$ Marketing Triangle" dan " $3^{2}$ Values-Based Matrix". Praktik pemasaran produk maupun pemasaran sosial menurut Andreason, penekanannya pada masyarakat luas yang langsung mempengaruhi perilaku serta kebutuhan atau kepentingan target sasaran sebagai dasar pertimbangan . Yayasan Nurul Ibad membangun citra mereknya di benak masyarakat sebagai konsumen melalui pelayanan mereka dengan menggunakan marketing communication mix yang terdiri delapan model komunikasi utama yang dikemukakan oleh Philiph Kotler.
\end{abstract}

Kata kunci: Komunikasi Pemasaran Terpadu, Pesan, Nurul Ibad 


\section{PENDAHULUAN}

Komunikasi pemasaran terpadu atau kini lebih dikenal dengan sebutan Integrated Marketing Communication (IMC) adalah sebuah konsep dimana suatu perusahaan mengintegrasikan dan mengkoordinasikan berbagai saluran komunikasi untuk mengirim pesan yang jelas, konsisten, dan meyakinkan berkenaan dengan perusahaan dan produknya. (Kotler dan Amstrong; 2005).

Definisi IMC menurut American Association of Advertising Agencies adalah "A concept of marketing communication planning that recognizes the added value of a comprehensive plan that evaluates the strategic roles of a variety of communication disciplines - for example, general advertising, direct response, sales promotion, and public relations - and combines these disciplines to provide clarity, consistency, and maximum communication impacts.

Sebuah konsep perencanaan komunikasi pemasaran yang memberikan nilai tambah terhadap suatu perencanaan yang mendalam dengan cara melakukan evaluasi terhadap peran strategis dari berbagai macam ilmu komunikasi dan mengkombinasikannya untuk menghasilkan keakuratan, konsistensi, dan efek komunikasi secara maksimal melalui integrasi dari pesan - pesan yang terpisah. Definisi tersebut memusatkan perhatiannya pada proses penggunaan seluruh bentuk promosi untuk mencapai dampak atau efek komunikasi yang maksimal. Namun beberapa pihak, antara lain Don Schultz dan rekan, menilai definisi tersebut masih sempit atau bersifat terbatas yang tidak menggambarkan komunikasi pemasaran terpadu yang sebenarnya. Schultz menginginkan perspektif yang lebih luas yang mempertimbangkan seluruh sumber daya yang tersedia. Menurut Schultz, IMC merupakan komunikasi antara pemasar dan pelanggan, berupa upaya untuk berbicara dengan orang-orang yang membeli maupun tidak membeli produk. Ini berarti mengundang respon, bukan cuma upaya monolog, tetapi juga tanggung jawab atas hasilnya.
Pendapat tokoh komunikasi pemasaran yang lain seperti DeLozier, Nickels dan Arens juga senada. Menurut M. Wayne DeLozier (1976), komunikasi pemasaran adalah dialog yang berkesinambungan antara penjual dan pembeli dalam satu arena pasar. William G. Nickels (1984) menyebut komunikasi pemasaran sebagai pertukaran informasi dua arah dan persuasi yang memungkinkan proses pemasaran berfungsi lebih efektif dan efisien. Sementara itu, William F. Arens (1996) mengartikan IMC sebagai proses menjalin dan memperkuat hubungan yang saling mengembangkan dan mengkoordinasikan program komunikasi strategis agar memungkinkan mereka melakukan kontrak konstruktif dengan perusahaan atau merek produk melalui berbagai media.

Konsep IMC muncul sejak tahun 1980, dimana Theodore Levitt (1976) dalam bukunya "Innovation in Marketing" memperkenalkan kata koordinasi dan integrasi di dalam beragam kegiatan promosi. Sebuah organisasi melihat bahwa pentingnya koordinasi dan integrasi dari berbagai elemen promosi dan aktivitas pemasaran lainnya untuk berkomunikasi dengan khalayaknya.

\section{Integrasi Kegiatan IMC}

Proses integrasi kegiatan komunikasi pemasaran diringkas secara sederhana oleh Chris Fill (1995) dalam sebuah model yang terdapat dalam buku karangannya, yaitu Marketing Communication. Model tersebut dapat dilihat pada gambar di bawah ini: 


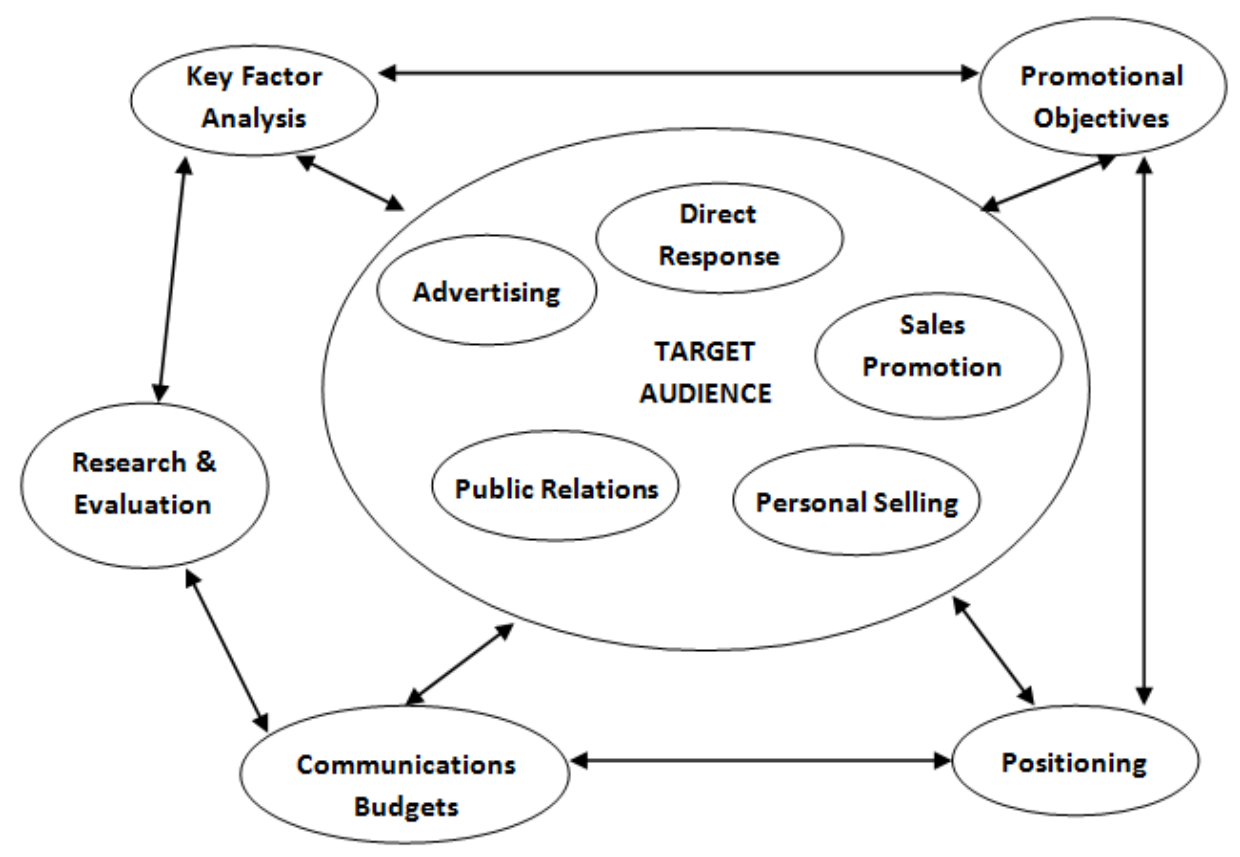

Gambar 1. Model Proses Integrasi Kegiatan Komunikasi Pemasaran Sumber: Chris Fill (1995)

\begin{tabular}{cccc}
\multicolumn{2}{c}{ Berdasarkan } & gambar 1 & dapat \\
dipelajari bahwa & proses & untuk
\end{tabular} mengintegrasikan kegiatan komunikasi pemasaran dilakukan dengan cara mengintegrasikan dari elemen - elemen dari komunikasi pemasaran yaitu advertising, direct response, sales promotion, public relation, dan personal selling untuk mengkomunikasikan pesan kepada target audiens. Sehingga setiap elemen dalam komunikasi pemasaran tidak dapat digunakan secara terpisah tetapi harus dikombinasikan untuk dapat menopang satu dengan yang lainnya.

Efektivitas dari proses integrasi kegiatan komunikasi pemasaran dapat dimaksimalkan dengan mempertim-bangkan tujuan dan sasaran dari komunikasi pemasaran, positioning merek produk dan atau merek perusahaan, anggaran yang dimiliki oleh perusahaan, hasil riset dan evaluasi, dan faktor - faktor yang mempengaruhi efektifitas dari kegiatan komunikasi pemasaran. Hal - hal tersebut harus dipertimbangkan secara matang di dalam mengintegrasikan elemen- elemen komunikasi pemasaran.

Petrison and Wang (1996), menyatakan beberapa penghalang dalam proses integrasi elemen komunikasi pemasaran, yaitu: tersedianya database pemasaran yang memungkinkan pemasar untuk mendesain komunikasi spesifik terhadap tipe-tipe konsumen tertentu, berkembangnya konsep niche marketing dan micro marketing, dimana konsep tersebut menerapkan pesan yang berbeda dan terpisah untuk setiap segmen konsumen. Adapun metode spesifik yang digunakan oleh praktisi periklanan pada tiap ragam alat komunikasi pemasaran mempengaruhi pesan yang disampaikan, sehingga menciptakan diversifikasi usaha atau departemen dalam perusahaan, serta perbedaan budaya secara nasional dan internasional sehingga suatu pesan tidak dapat dicerna dengan baik untuk budaya yang berbeda.

Banyak pengelola pemasaran saat ini, dan juga biro iklan, mulai menggunakan pendekatan IMC dan menerapkan komunikasi total untuk menciptakan dan mempertahankan hubungan atau merek dan pelanggannya. Walaupun sebagian kalangan masih mempertanyakan IMC sebagai suatu tren yang bersifat permanen namun pendekatan IMC terbukti mampu menawarkan nilai yang sangat berarti bagi pengelola pemasaran di tengah lingkungan komunikasi yang berubah dengan cepat. 
Ada beberapa faktor yang mempengaruhi perkembangan konsep dari IMC (Blythe,2003), yaitu: perubahan pada pasar konsumen dan perubahan pada pasar bisnis.

Perubahan pasar konsumen ditandai disebabkan oleh luapan informasi yang timbul akibat meningkatnya jumlah pesan pesan komersial. Iklan di media massa mulai mengalami penurunan dalam menarik perhatian dari konsumen. Di sisi lain, media iklan telah tersegmentasi dalam beberapa kelompok media, sehingga meningkatkan jumlah produk imitasi yang tidak memiliki keunikan khusus dibandingkan dengan produk pesaingnya. Selain itu, meningkatkan penggunaan media untuk menarik perhatian dari masyarakat terhadap tanggung jawab sosial perusahaan. Perubahan pada pasar bisnis menyebabkan terjadinya proses merger, akusisi, dan perubahan struktur organisasi dan manajemen pada perusahaanperusahaan. Ketertarikan pihak manajemen perusahaan terhadap hasil jangka pendek, sehingga meningkatkan pemahaman akan pentingnya strategi komunikasi serta meningkatnya pemahaman akan pentingnya komunikasi internal perusahaan yang baik.

\section{IMC pada organisasi nirlaba}

Komunikasi pemasaran terpadu yang diterapkan pada lembaga non-profit oriented atau lebih populer disebut organisasi nirlaba mengalami pengembangan, karena disesuaikan dengan kebutuhan lembaga itu sendiri. Pada lembaga non-profit oriented, komunikasi pemasaran terpadu dikenal sebagai komunikasi pemasaran sosial. Perbedaan mendasar antara "pemasaran komersil" dan "pemasaran sosial", menurut Andreason adalah pada prinsip "4 P" yang dikenal sebagai marketing mix. Di dunia bisnis "4P", adalah promotion (promosi), price (harga), product (produk) dan place (tempat). Dalam komunikasi pemasaran sosial ada dua hal lain yang membuat berbeda, yaitu adanya partnership (kemitraan) dan policy (kebijakan).

Pada prinsipnya, praktik komunikasi pemasaran sosial tak ada artinya apabila kemitraan tidak dijadikan tujuan organisasi. Demikian pula tak ada artinya upaya mengubah perilaku melalui pemasaran sosial apabila tidak diikuti atau dilanjutkan dengan upaya mendorong tersusunnya sebuah kebijakan. Penerapan social marketing, tujuannya bukan semata-mata fund raising (memperoleh dana) karena dalam kenyataan social marketing juga berarti menyampaikan gagasan secara efisien dan tepat.

Komunikasi pemasaran sosial atau social marketing adalah aplikasi dari teknik pemasaran komunikasi bisnis ke dalam analisis, perencanaan, eksekusi, dan evaluasi program-program organisasi nirlaba yang telah dirancang berdasarkan target individual dalam rangka meningkatkan kesejahteraan personal, serta memenuhi kebutuhan manusia secara sensitif dan memuaskan.

Pada dasarnya social marketing adalah strategi "menjual" gagasan untuk mengubah pemikiran, sikap dan perilaku masyarakat. Berdasarkan pengalaman, penerapan strategi pemasaran dalam dunia sosial terbukti dapat memberdayakan organisasi dalam memperoleh dukungan untuk melanjutkan hidupnya, antara lain dalam memperoleh sumber dana potensial yang berasal dari masyarakat secara luas (fund raising). Ada 'benang penghubung' antara dunia bisnis dan sosial yang terkadang luput dari perhatian kita. Ketika bicara bisnis, para pebisnis kerap kali lupa bahwa mereka juga harus membawa nilainilai sosial. Sebaliknya, pelaku di dunia sosial seringkali lupa untuk bersikap profesional sehingga tak hanya dapat dipercaya pemberi dana atau penyumbang, melainkan juga bekerja secara efisien dan bagus. Hal yang menarik untuk disimak adalah bagaimana posisi social marketing dan cara pandang praktisi bisnis dan marketing bisnis. Hermawan Kertajaya memaparkan bahwa komunikasi pemasaran sosial termasuk dalam salah satu pilihan bagi pebisnis atau perusahaan untuk berbuat baik.

Di dunia bisnis kini perusahaan dinilai "besar" oleh capital market dan publik apabila melakukan kebaikan demi kemanusiaan." Sebagaimana dituangkan Kotler bersama rekannya Nancy Lee dalam bukunya "Corporate Social Responsibilty", dengan istilah "Doing Great by Doing Good".

Kini di berbagai belahan dunia, perusahaan-perusahaan besar seolah 
berlomba melaksanakan Corporate Social

Responsibilty (CSR). Program ini merupakan kegiatan yang sifatnya sukarela dan bukan bertujuan komersil dengan menyisihkan sejumlah dana untuk kemanusiaan dan kemasyarakatan. Ini ada berkaitan erat dengan kebijakan pajak di negara barat. Ada semacam kebijakan pajak kepada perusahaan apabila menyisihkan dana untuk kegiatan sosial ke masyarakat berupa potongan pajak. Melalui kebijakan ini, perusahaan memperoleh insentif pajak sekaligus memperoleh keuntungan lain berupa penilaian positif dari pasar dan juga publik.

Organisasi nirlaba berbeda dari lembaga bisnis atau perusahaan dalam hal tujuan dan pelaksanaan program, namun perusahaan dan pebisnis harus selalu ingat social values, sedangkan organisasi nirlaba dan para aktivisnya harus memiliki kinerja dan sikap profesional dalam menjalankan program-programnya.

Praktik social marketing paling mendasar adalah dengan mengaitkan nilai inti (core value) organisasi nirlaba dengan perubahan perilaku masyarakat yang diperlukan. Tentu saja social marketing berperan penting karena dapat menganalisa perilaku berdasarkan nilai-nilai yang berlaku, memilih kelompok sasaran dan perilaku yang perlu diubah serta "menjual" gagasan perubahan.
Berdasarkan definisi dari para ahli, social marketing pada dasarnya merupakan aplikasi strategi komunikasi pemasaran komersil untuk "menjual" gagasan dalam rangka mengubah sebuah masyarakat, terutama dalam manajemen yang mencakup analisa, perencanaan, implementasi dan pengawasan. Organisasi nirlaba perlu memahami dan merancang strategi social marketing berdasarkan pemahaman ini? Selain penerapan sembilan elemen marketing yang telah dikenal (segmentasi pasar, target, positioning, diferensiasi, marketing mix, selling, brand, service dan process), pada dasarnya marketing menurut Hermawan Kertajaya adalah sesuatu yang sederhana. Ia mengumpamakannya sebagai seni "menjual" diri (selling self) atau umumnya merepresentasikan organisasi tertentu. Apabila seseorang atau organisasi mempraktikkan prinsip promosi tanpa memaksa, lalu memahami dan menerapkan positioning secara tepat, memahami branding dan diferensiasi berarti lembaga atau seseorang perusahaan telah menjalankan marketing dengan benar. Hermawan mengistilahkan dasar-dasar marketing sebagai "3i Marketing Triangle", yang diilustrasikan dalam gambar berikut: 


\section{3i Marketing Triangle}

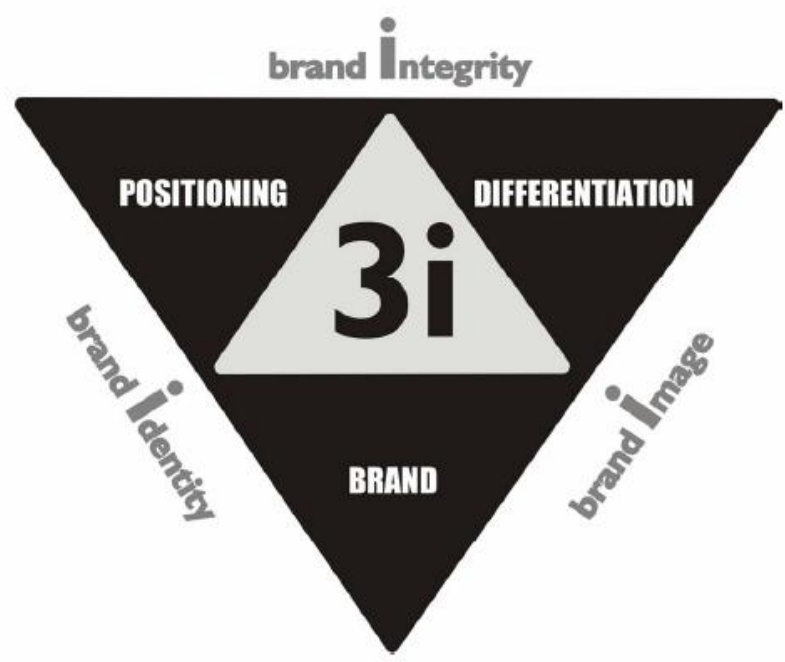

MarkPlus\&Co

Gambar 2. Model 3i Marketing Triangle menurut Hermawan Kertajaya

Sumber: Kotler, 2010:36

Adapun " $3 i$ Marketing Triangle" terdiri dari: positioning (cara sasaran atau publik yang hendak diubah perilakunya mendefinisikan perusahaan atau organisasi dengan kompetitor), differentiation (perbedaan) dan brand (keunikan, ketajaman, dan fokus sebuah produk dibandingkan dengan produk lainnya, bisa berupa logo dan bentuk unik). Hermawan telah menjelaskan pada bab "Mengapa Social Marketing?" Hermawan menjelaskan betapa dunia bisnis masa kini dan yang akan datang tidak lagi berseberangan dengan organisasi nirlaba. Selain karena adanya pergeseran nilai, dunia bisnis memandang penting mengedepankan nilai-nilai sosial (social values) dan adanya peluang bagi organisasi nirlaba hidup berdampingan secara sinergis, misalnya melalui program CSR. Hal lain adalah pentingnya organisasi nirlaba mengadopsi profesionalisme korporasi dalam bekerja dan memberikan servis, berkaitan dengan kaidah pemasaran umum.
Berdasarkan pengalamannya, Hermawan berpendapat, pemasaran di masa kini menjadi lebih berhasil apabila memperbanyak strategi pemasaran horisontal (dari individu ke individu). Misalnya, dengan membuat situs web. Caracara vertikal seperti menggunakan metode komunikasi satu arah kini kurang efektif. Hal serupa berlaku untuk social marketing. Pemasaran seharusnya tidak dipandang hanya sebagai sebuah alat atau seolah anggota tubuh, melainkan sebuah menyeluruh (the whole). Menurut Hermawan, di masa kini visi, misi dan nilainilai organisasi tidak hanya melibatkan intelektualitas (mind) dan hati (heart), melainkan juga ruh (spirit). Operasionalisasi tiap elemen tersebut dapat dilihat pada gambar " 32 Values-Based Matrix" sebagai berikut: 


\section{$3^{2}$ Values-based Matrix}

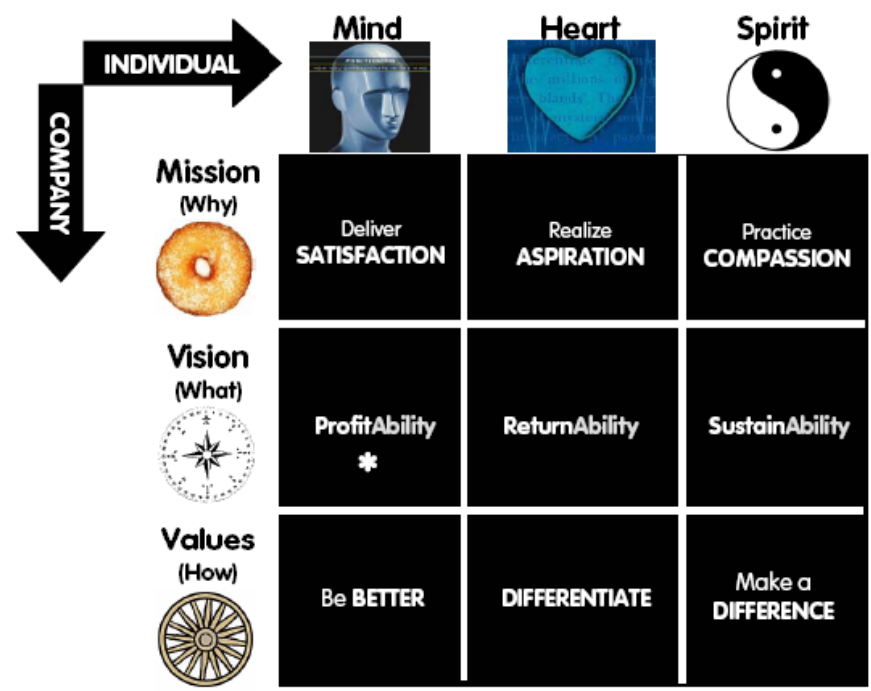

* ProfitAbility for Nonprofit Organizations means the ability to gather and manage donation, charity, etc from corporations and from the public.

Gambar 3. Model $3^{2}$ Values-based Matrix menurut Hermawan Kertajaya Sumber: Kotler, 2010:42

Penerapan teknik pemasaran dalam melaksanakan program-program organisasi nirlaba membutuhkan strategi. Tentu saja strategi yang digunakan sedikit berbeda dibandingkan dengan memasarkan produk barang. Menurut Linda D. Ibrahim perbedaan yang prinsip terletak pada tambahan "2 P" pada marketing mix bisnis yang hanya terdiri dari "4 P", yaitu partnership (kemitraan) dan policy (kebijakan).

\section{Pemasaran Sosial Yayasan Nurul Ibad}

Layaknya Yayasan pendidikan pada umumnya, Yayasan Nurul Ibad juga melakukan kegiatan pemasaran untuk membuat masyarakat tahu tentang keberadaan yayasan ini. Salah satu cara yang digunakan untuk membentuk image konsumen adalah melalui komunikasi pemasaran. Key Informan dari penelitian ini yaitu Ibnu Mulkan Ketua Pondok Pesantren Nurul Ibad mengemukakan adanya kegiatan pemasaran yang dilakukan oleh Yayayan Nurul Ibad. Yayasan Nurul Ibad membangun citra mereknya di benak masyarakat sebagai konsumen melalui pelayanan mereka dengan menggunakan marketing communication mix yang terdiri delapan model komunikasi utama yang dikemukakan oleh Philiph Kotler.

A. Iklan (Advertising).

Iklan merupakan salah satu jenis komunikasi pemasaran yang paling banyak dikenal oleh masyarakat. Iklan digunakan oleh pemasar untuk menarik konsumen dengan pesan tentang informasi produk agar konsumen melakukan transaksi pembelian, selain itu iklan juga dapat digunakan untuk membentuk kesan terhadap produk atau Yayasan Nurul Ibad menggunakan periklanan dalam bentuk spanduk, pamflet, brosur dan stiker. Nurul Ibad tidak menggunakan iklan lini atas dan hanya menggunakan iklan lini bawah. Hal ini didasari dengan alasan bahwa iklan lini bawah lebih mudah diterima masyarakat sekitar lokasi yayasan di Lubang Buaya, Jakarta Timur.

Jurnal Bricolage Vol. 2 No. 2 
B. Promosi Penjualan.

Promosi penjualan sudah lazim dilakukan oleh sebuah perusahaan untuk menarik minat pembeli sekaligus memberi dorongan agar calon pembeli segera melakukan tindakan pembelian. Promosi penjualan dalam bentuk beasiswa penuh, potongan harga dan cicilan juga dilakukan oleh Yayasan Nurul Ibad.

C. Acara dan Pengalaman bisa dikategorikan sebagai yayasan yang memiliki event tahunan yang cukup banyak. Acara rutin yang dilakukan adalah peringatan acara besar keagamaan, santunan rutin, bakti sosial, open house, parenting.

D. Hubungan masyarakat dan Publisitas.

Hubungan Masyarakat dapat memberikan informasi terkait perusahaan dalam upayanya untuk mengontrol citra perusahaan. Melalui kegiatan dan acara yang dilakukan, Nurul Ibad telah banyak melakukan publisitas sehingga berita acara tersebut sampai di masyarakat. Salah satu bentuk publikasi yang dilakukan adalah melalui peliputan media dari event yang dilaksanakan dengan mengundang tokoh-tokoh masyarakat dan Pejabat Negara.

E. Pemasaran Langsung (Direct Marketing).

Pemasaran langsung adalah penjualan secara tatap muka langsung dan berkomunikasi secara personal dengan tidak melibatkan media massa. Nurul Ibad tidak menggunakan pemasaran langsung.

F. Pemasaran Melalui Internet (Interactive/Internet Marketing).

Nurul Ibad secara aktif juga menggunakan media sosial sebagai penyebar informasi tentang yayasan nurul ibad kepada masyarakat. Informasi yang disebarkan melalui media sosial seperti website dan facebook tersebut merangkum banyak hal, mulai informasi kegiatan, kurikulum hingga informasi pendaftaran.
G. Word of Mouth / Komunikasi Pemasaran dari mulut ke Mulut.

Pemasaran dari mulut ke mulut atau word of mouth sangat membantu pemasaran karena melalui pemasaran dari mulut ke mulut informasi tentang produk yang ditawarkan akan menjangkau calon konsumen yang mungkin tidak bersinggungan dengan promosi secara langsung. Yayasan Nurul Ibad, yang menawarkan jasa pendidikan juga merasakan manfaat kegiatan word of mouth untuk meyakinkan masyarakat mengenai kualitas pendidikan yang diberikan oleh Nurul Ibad.. Hal ini sama dengan pengertian pemasaran dari mulut ke mulut atau word of mouth yang dikemukakakan oleh Philip Kotler dan Kevin Lane Keller. Pemasaran dari mulut ke mulut adalah komunikasi lisan, tertulis, dan elektronik antar masyarakat yang berhubungan dengan keunggulan atau pengalaman membeli atau menggunakan produk atau jasa.(Kotler dan Keller : 2008)

H. Personal Selling / Penjualan Personal. Penjualan personal atau Personal selling merupakan komunikasi yang dilakukan secara individual. Berbeda dengan cara pemasaran lainnya, hubungan yang tercipta dalam penjualan personal lebih intens dan bersifat pribadi karena penjual dapat mengetahui motif dan apa yang diinginkan oleh calon pembeli. (Haryanto: 2012)

I. Komunikasi Pemasaran dan Pelayanan Membangun Brand Image melalui komunikasi pemasaran yang baik, nurul ibad membangun image yang baik di masyarakat terutama bagi konsumennya. Citra merek yang dibangun oleh nurul ibad dilakukan melalui pemberian pelayanan yang baik bagi konsumen dan kemudian menuliskannya melalui iklan yang diberikan kepada masyarakat. Pembentukan kesan yang baik bagi Yayasan Nurul Ibad dilakukan dengan memaksimalkan pelayanan kepada konsumen. Sikap Konsumen dan Kesediaan melakukan Word of Mouth dari pengalaman dan kesan yang

Jurnal Bricolage Vol. 2 No. 2 
dilakukan oleh Nurul Ibad. Orangtua murid besedia menceritakan ke kolega dan mengawali kegiatan komunikasi pemasaran dari mulut ke mulut.. Citra merek yang dibangun oleh nurul ibad melalui pelayanan yang baik, memberikan kesan yang baik bagi konsumen sehingga mereka bersedia melalukan pemasaran dari mulut ke mulut. Pemasaran dari mulut ke mulut inilah nantinya yang membuat citra nurul ibad semakin baik. Selain ini dengan pemasaran mulut ke mulut, seakan mendukung setiap slogan yang dipilih nurul ibad dalam beriklan baik melalui iklan spanduk, pamflet maupun brosur.

Kesimpulannya Yayasan Nurul Ibad dalam menimbulkan atau menciptakan brand image untuk nurul ibad menggunakan marketing communication mix yang dikemukakan Philip Kotler dan Kevin Lane Keller yang terdiri dari advertising (Iklan), sales promotion (promosi penjualan), direct marketing (penjualan), interactivel internet marketing (pemasaran melalui internet), public relations (publikasi/ hubungan masyarakat), acara dan pengalanan, word of mouth (pemasaran mulut ke mulut), dan personal selling (penjualan tatap muka). Iklan yang digunakan adalah iklan lini bawah. Iklan tersebut meliputi spanduk, pamflet, brosur dan stiker. Promosi penjualan juga dilakukan oleh nurul ibad melalui beasiswa penuh, potongan harga, cicilan, dan penawaran sample produk berupa sit in. Acara dan Pengalaman dilakukan oleh nurul ibad untuk memasarkan sekolah alam nurul ibad, acara tersebut meliputi acara rutin memperingati hari besar kegamaan, santunan, bakti sosial, open house, peringatan hari bumi dan parenting. Hubungan masyarakat dan publisitas didapat melalui pemberitaan di media massa. Pemasaran langsung tidak dilakukan oleh nurul ibad. Sedangkan pemasaran interaktif dilakukan oleh nurul ibad melalui facebook dan website. Pemasaran dari mulut ke mulut atau Word of Mouth, juga dilakukan oleh orangtua murid sebagai pihak yang merasakan kebermanfaatan nurul ibad. Ini mereka lakukan karena pelayanan nurul ibad yang baik. Sedangkan penjualan tatap muka dilakukan oleh nurul ibad melalui setiap kepala sekolah masing-masing jenjang dan staff administrasi. Berdasarkan uraian data diatas, peneliti menyimpulkan bahwa terbentuknya citra merek yang baik di benak konsumen Yayasan nurul ibad melalui beberapa hal :

1. Acara yang setiap tahunnya memberikan kesan yang baik untuk nurul ibad sebagai sekolah alam yang fun dan menyenangkan bagi anak belajar.

2. Kesan konsumen terhadap nurul ibad juga terbentuk melalui pemasaran interaktif yang dilakukan oleh nurul ibad melalui facebook dan website.

3. Nurul ibad memberikan pelayanan yang maksimal sehingga konsumen merasa puas dengan pelayanan yang diberikan oleh staff dan karyawan serta guru nurul ibad kepada mereka. Ini juga menjadi pemicu timbulnya kerelaan orangtua siswa melakukan pemasan dari mulut ke mulut (word of mouth).

4. Keunggulan nurul ibad yang terbentuk melalui materi pembelajaran, fasilitas dan pelayanan yang maksimal membuat konsumen tidak merasa keberatan melakukan kegiatan pemasaran dari mulut ke mulut untuk membangun citra merek yang baik bagi nurul ibad.

\section{PENUTUP}

Praktik pemasaran sosial tak ada artinya apabila kemitraan tidak dijadikan tujuan organisasi. Menurut Andreason, penekanannya adalah pada masyarakat luas, langsung mempengaruhi perilaku dan kebutuhan atau kepentingan target sasaran sebagai dasar pertimbangan. Demikian pula, social marketing tak ada artinya apabila tidak diikuti atau dilanjutkan dengan upaya mendorong tersusunnya sebuah kebijakan. Salah satu contoh pembentukan sistem kebijakan adalah adanya tax reduction (pemotongan pajak) bagi lembaga atau

Jurnal Bricolage Vol. 2 No. 2 
korporasi yang menyumbang. Pajak yang jumlahnya reduksi ini bisa menjadi bagian dari advokasi organisasi nirlaba sehingga pada akhirnya organisasi tidak tergantung semata-mata kepada donor.

Komunikasi publik dan pemasaran sosial dapat bertemu pada dua hal. Yaitu, "public communication of public interest" dan "involving public" ("Public Communication Campaigns", Ronald E. Rice \& Charles K. Atkin, Sage, 2000). Jadi, keduanya merupakan upaya komunikasi publik untuk menyuarakan kebutuhan masyarakat dan sifatnya melibatkan masyarakat. Keduanya tak terpisahkan dan saling mempengaruhi.

Mengapa upaya menyampaikan gagasan untuk mengubah perilaku masyarakat kerapkali kurang berhasil? Atau, bahkan gagal? Salah satu penyebab, adalah gagalnya organisasi dalam melakukan komunikasi publik. Atau, bisa jadi gagasan organisasi tidak sejalan dengan kebutuhan masyarakat. Menurut pakar komunikasi, Effendi Ghazali, masalah komunikasi publik dan pemasaran sosial di Indonesia pada umumnya disebabkan karena: 1.) Publik kurang dianggap penting di Indonesia, dan akhirnya komunikasi publik kurang berkembang. Publik selama ini lebih diwakili oleh sekelompok orang dalam aksi demo, misalnya : Media massa sedang ada di masa transisi dari sistem otoriter ke libertarian; Komunikasi publik sering tercampur dengan sosialisasi, dan Pemasaran sosial sering tercampur dengan kehumasan (Public Relation).

Pada akhirnya, dibutuhkan sebuah proses yang cukup panjang agar semua proses "belajar" masyarakat berjalan lancar. Konsultasi publik adalah bagian dari public communication. Public relation merupakan salah satu alat untuk konsultasi publik. Cara melakukannya adalah dengan menyelenggarakan forum komunikasi untuk mengonsultasikan dengan publik tentang kepentingan publik antara pihak tertentu dengan aneka stakeholders yang telah dianalisis sedemikian rupa relevansinya dengan kepentingan publik yang ingin dibahas. Pentingnya $70 \%$ "Konsultasi
Publik" dan 30\% saja "Sosialisasi". Yang sering terjadi di Indonesia adalah tidak dilakukannya konsultasi publik, yang diganti dengan penonjolan "sosialisasi". Sosialisasi yang dimaksud adalah dalam konteks "memaksa" atau "mempersuasi" masyarakat untuk menerima suatu kebijakan pemerintah

Perlu dilakukan pembahasan tentang keberhasilan maupun kegagalan komunikasi pemasaran sosial yang dilakukan oleh nurul ibad untuk membangun citra merek. Sehingga kedepannya dapat dimaksimalkan penggunaan komunikasi pemasaran dalam membangun citra merek, hal ini tentu saja di kaitkan dengan kebutuhan konsumen.

Pelayanan, fasilitas dan kurikulum nurul ibad yang berbeda sebaiknya lebih banyak dirangkum dan disampaikan dalam setiap komunikasi pemasaran yang dilakukan. Baik melalui program yang dipublikasikan maupun iklan dan jenis komunikasi pemasaran lainnya sehingga pesan yang diinginkan nurul ibad tentang citra sekolah alam nurul ibad dapat lebih cepat terbentuk di masyarakat

Sebuah organisasi sebaiknya mengarahkan kehumasan pada pemasaran sosial yang sesungguhnya. Langkah awalnya adalah dengan menciptakan makna bersamasama dengan publik yang menjadi sasaran program. 


\section{DAFTAR PUSTAKA}

Blythe, J.. 2003. Essential of Marketing Communications 2nd Edition. England: Pearson Education

DeLozier, M. Wayne. 1976. The Marketing Communications Process.: Tokyo: McGraw-Hill Kogakusha, Ltd.

Fill, Chris. 1995. Marketing Communications: Frameworks, Theories and Applications. London: Prentice Hall

Kotler, Philip. 2000. Marketing Management 10th Edition. Upper Saddle River: Prentice Hall, Inc.
Kotler, Philip. 2000. Marketing 3.0: From Products to Costomers to the Human Spirit.. Hobokken, New Jersey: John Willey \& Sons, Inc.

Levitt, Theodore. 1976. Innovation In Marketing: New Perspectives For Profit And Growth. USA: McGraw-Hill

Nickels, William G. .1984. Marketing Communication And Promotion: Text And Cases. Columbus: Grid Publishing. Inc.

Petrison, L. A. and Wang, P. 1996. Integrated Marketing Communication: An Organizational Perspective. Marwah: Lawrence Erlbaum 